\title{
The curious naturalist
}

\section{Niko Tinbergen was one of the founders of ethology.}

\author{
Niko's Nature \\ by Hans Kruuk \\ Oxford University Press: 2003. 406 pp. $£ 20$

\section{John Krebs}

It was 1965 . Niko Tinbergen, a small, whitehaired, bespectacled man of modest manner, was in full flow in one of his enchanting undergraduate lectures. Suddenly, he leapt onto the front bench of the steeply raked Victorian lecture theatre, strode from bench to bench past astonished students right up to the back, snatched a newspaper from the grasp of an inattentive undergraduate, and pranced gazelle-like down the benches to the front. And all without pausing in his explanation of how some oystercatchers pierce mussel shells by stabbing whereas others hammer them open. I remember being both relieved and astounded: relieved that I wasn't the one with the newspaper, and astounded by Tinbergen's athletic burst. As a second-year undergraduate at the University of Oxford, I didn't know that as a young man he had played international hockey in Holland.

His athletic prowess is one of many charming glimpses of Tinbergen in Hans Kruuk's thoroughly researched biography, an account that is affectionate and sympathetic, while at the same time being dispassionate and appraising. Kruuk was a student (or "pupil" as Tinbergen called them), friend and admirer of Tinbergen and so writes with the authority of first-hand knowledge. But this is no dewy-eyed romantic reinvention of a hero 20 years after his death.

Tinbergen was a major figure in twentiethcentury biology. As co-founder of the biological study of animal behaviour known as ethology, he shared the Nobel Prize with Konrad Lorenz and Karl von Frisch in 1973 and, like all creative scientists, he set the research agenda for generations of followers.

His approach to the science of animal behaviour is perhaps best captured in the title of one of his classic books, Curious Naturalists. Tinbergen observed and wondered. He turned observation into ingenious experiment, description into analysis, and natural history into science.

Growing up in the Netherlands in the early twentieth century as the son of a school teacher, he joined the Dutch Youth League for Nature Study. This helped him develop his skills as a naturalist and his talent as an artist - the biography is illustrated with many of his sketches. Perhaps because the Netherlands is a small, crowded country, Tinbergen's love of nature was expressed in his eye for detail and the beauty in the
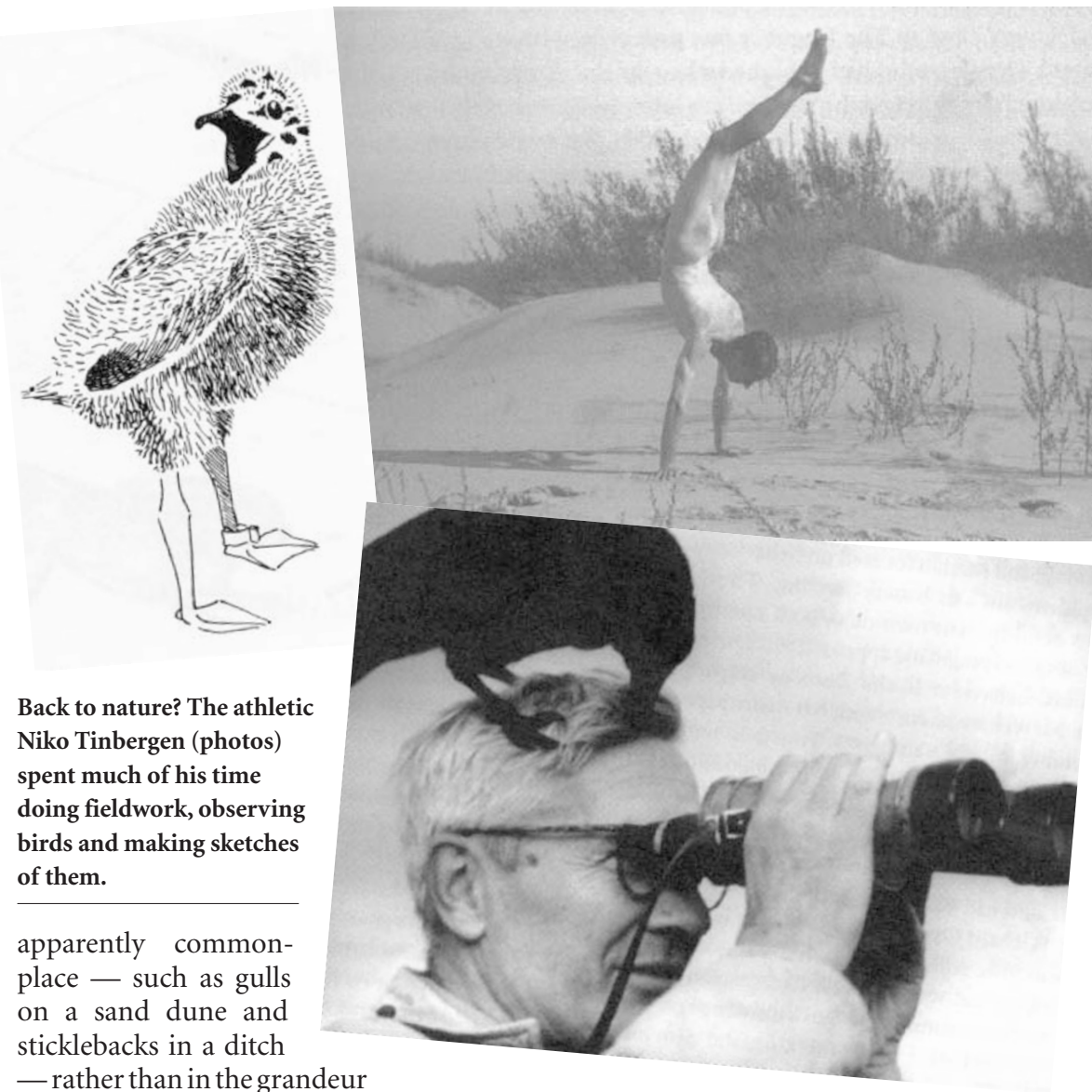

Back to nature? The athletic Niko Tinbergen (photos) spent much of his time doing fieldwork, observing birds and making sketches of them.

apparently commonplace — such as gulls on a sand dune and sticklebacks in a ditch — rather than in the grandeur of great tracts of wilderness.

Looking back at Tinbergen's scientific work, Kruuk sees some contradictions. Tinbergen created and cultivated the idea that great insights into the natural behaviour of animals could be derived from simple, elegant experiments. But, as Kruuk skilfully exposes, many of Tinbergen's experiments were far from perfect in their design, execution and analysis. This did not diminish their importance and impact either in the scientific community or in the eyes of the general public, however. Tinbergen was a great popularizer of scientific research, and many wildlife programmes on television took as their source the work of Tinbergen and his students. This reached its zenith when his film Signals for Survival won the Italia Prize for TV documentaries in 1969.

In his early career at the University of Leiden, Tinbergen created, together with Lorenz, a theoretical framework for ethology, summarized in his seminal 1951 book The Study of Instinct. Within a few years of its publication, this framework of innate drives, releasing stimuli and consummatory behaviours had come under telling attack by Danny Lehrman and Robert Hinde. Nevertheless, the clarity of Tinbergen 's argument, even when it

was later shown to be inadequate, shone a light for others to see a way forward.

By contrast, much of Tinbergen's work following his move to Oxford in 1949 was less influenced by theory, comprising instead a series of elegant stories that were increasingly concerned with the function as well the causation of behaviour, each one a gem but not knitted together as a coherent whole. This was despite the fact that with his new colleagues - notably David Lack, Charles Elton, George Varley, Arthur Cain and Bernard Kettlewell — he had the potential to weave together ethology, population biology and evolution. This blending, to create ethology's offspring behavioural ecology, had to wait for the next generation.

A recurrent theme in Kruuk's book is Tinbergen's guilt about being paid to do what he liked best as a hobby: watch animals in the wild. As he wrote in Curious Naturalists: "It is I think only natural for a man to have occasional doubts about the value of what he is doing, at any rates such doubts have often occurred to me... A little devil seems to look over our shoulder and to take great pleasure in kindling this spark of doubt."

This was a major motivator for him to 
turn in the last part of his career to the ethology of man. In the 1960s, Desmond Morris's The Naked Ape and Lorenz's On Aggression - both engaging, if flawed, books - had thrown open the whole debate about the extent to which present-day human behaviour can be explained in terms of our evolutionary past. If our evolutionary history provides explanations, perhaps it also provides clues to the treatment of dysfunctional or abnormal human behaviour.

Tinbergen's venture into this area did not attract widespread support. His work, with his wife Lies, on the ethology of childhood autism was seen by many as too anecdotal and simplistic, and his Nobel lecture, in which he talked about both autism and the rather wacky Alexander technique for improving body posture, would, in the words of Kruuk "be best forgotten".

In addition to his comprehensive account of Tinbergen the scientist, Kruuk also discusses Tinbergen the man. He offers insights into Tinbergen's relationships with his wife and children, his siblings, including his older brother Jan, who won a Nobel Prize for economics in 1969, and with his students and colleagues. Kruuk also discusses in detail the recurrent depression that afflicted Tinbergen, especially during the last 20 years of his life, which impaired his capacity for work.

Kruuk succeeds in conveying the complexity of Tinbergen's personality. Tinbergen was self-effacing, modest and charming, totally without pomposity, haunted by selfdoubt, but was at the same time demanding of himself and others, ambitious, charismatic and a natural showman and leader. He was legendary for his rigorous powers of analysis (all of us who participated in his weekly seminars have our own favourite stories of his clinical dissection of any hapless speaker with leaky intellectual plumbing), but he often relied on intuition and creative leaps in drawing conclusions.

What of his lasting contribution to science? Where has ethology gone since Tinbergen's death? Some of the people Kruuk quotes think it is "as alive and strong as ever", whereas others say it has evolved into behavioural ecology and animal cognition.

The prognosis offered some 20 years ago by Robert Hinde in his Niko Tinbergen lecture is more inclusive. He argued that the lasting influence of ethology, and therefore of Tinbergen's work, would be felt by the interaction of its ideas and approaches with many other fields, such as anthropology, neuroscience, psychiatry, psychology, evolution and ecology. It is now widely accepted that it is possible to analyse the behaviour of animals in their natural environment with rigour and precision. Niko showed us how to do it.

John Krebs is in the Department of Zoology,

University of Oxford, South Parks Road,

Oxford OX1 3PS, UK.

\section{Chemistry's bag of tricks}

\section{From Elements to Atoms: \\ A History of Chemical Composition (Transaction 92-4) \\ Robert Siegfried \\ American Philosophical Society: 2003. \\ 278 pp. $\$ 24$ \\ Bernadette Bensaude-Vincent}

As a scholar for more than 40 years, Robert Siegfried says he has witnessed the emergence of the history of science as an academic specialty, and would like to see it included in the scientific curriculum. With such didactic purposes in mind, he deliberately runs counter to the current historiographical mainstream.

Siegfried's view is that chemistry evolved from a metaphysical idea of composition into an experiential, positive idea of composition, forged by AntoineLaurent Lavoisier and completed by John Dalton's atomic theory. In so doing, Siegfried advocates a positivistic view that has been heavily criticized by a generation of historians of science. He also purposefully writes history from a presentday perspective.

On top of that, he focuses on the chemists' philosophy of matter, even though the interest of many historians shifted long ago from concepts to practices and the social dimensions of science. He quotes several recent historical studies of the same period, but never engages in historiographical debates. This is "my story", he claims, just one interpretation among many others. In his view, history is "a bag of tricks that we play on the dead".

But despite his old-fashioned approach, Siegfried's account of eighteenth-century chemistry is not too dissimilar from other recent descriptions. Like Frederic L. Holmes in his book Eighteenth-century Chemistry as an Integrative Enterprise (University of California, 1989), he stresses the importance of salt chemistry, which provided the empirical core of modern chemistry. And like Ursula Klein (Science in Context 7, 163; 1994), he assumes that analysis and synthesis played a key role in the emergence of an empirical concept of composition. He agrees with most historians of chemistry that combustion was not the major issue discussed in the eighteenth century, and that phlogiston theory was by no means the overarching doctrine that dominated all chemical works before Lavoisier. In fact, it only really became a theoretical framework when chemists started investigating dozens of 'airs' in the 1770s.

In other words, Siegfried does not read eighteenth-century chemistry 'backwards' as an empty period preparing the stage for Lavoisier's chemical revolution. Instead, he provides a fine and nuanced account of many of the achievements that pre-dated

Lavoisier, such as the measurement by Torbern Bergman of the relative quantities of phlogiston in metals.

Even so, Siegfried's choice of a present-day perspective distorts this penetrating and thoughtful insight into chemistry's past. How relevant is a historical narrative that focuses on the absence of what would emerge later? In this book, Siegfried repeatedly points out what was lacking - a clear distinction between concepts, and a clear notion of what chemical substances are - and traces anticipations and prefigurations of notions that would only be explicit by Lavoisier or Dalton. Wouldn't it be more useful for students to try to understand how chemists of the past constructed their own views and notions? But Siegfried assumes that chemists before Lavoisier had no theory of their own, no coherent system and were philosophically inconsistent, thereby encouraging the view of a theory-free experimental practice that sounds at odds with the project of describing exclusively their philosophical notions.

Siegfried's assumption that "chemical composition has had no fundamental conceptual change" since Lavoisier and Dalton suggests that there is no history of chemical atomism since Dalton's atomic theory. Furthermore, the book's title, From Elements to Atoms, suggests that the idea of the element is now obsolete and that modern chemistry focuses exclusively on the atom. This is a view that many chemistry teachers will no doubt debate.

Bernadette Bensaude-Vincent is in the Department of Philosophy, Université de Paris X, 92001 Nanterre Cedex, France. 